\title{
The development of children's concepts of invisibility
}

\author{
Jacqueline D. Woolley and \\ University of Texas \\ Melissa A. McInnis \\ University of Alabama
}

\begin{abstract}
One of the most striking examples of appearance-reality discrepancy is invisibility - when something has no appearance yet still exists. The issue of invisibility sits at the juncture of two foundational ontological distinctions, that between appearance and reality and that between reality and non-reality. We probed the invisibility concepts of 47 3-7-year-olds using two sets of tasks: (1) an entity task, in which children were queried about the visibility and reality status of a variety of both visible and invisible entities, and (2) two standard appearance-reality tasks. Results showed that children's concepts of visibility and reality status are intertwined, and that an understanding that some entities are impossible to see develops between the ages of 3 and 7 .
\end{abstract}

\section{Keywords}

Invisibility; Reality; Appearance

\section{Introduction}

Visual input is a primary source of information about the environment. It allows us to know the color of something, the shape, the size, and a whole host of other properties. At a young age, children recognize the importance of vision as a source of information about the world (Piaget, 1962; Meltzoff, Waismeyer, \& Gopnik, 2012; Rogoff, Paradise, Arauz, CorreaChávez, \& Angelillo, 2003; Williamson, Jaswal, \& Meltzoff, 2010). Perhaps most importantly, we regularly use vision to confirm existence. If, for example, my child thinks she has lost her stuffed bear, my spotting of the bear under her bed will confirm the bear's location and, more importantly, its existence. Similarly, if she tells me there is an alligator under her bed, I can disconfirm this report by looking under her bed and informing her that there is nothing there. Yet visibility is not a foolproof indicator of existence, nor is existence a direct line to visibility. There are, in the real world, objects and events that we can see but

Correspondence concerning this article should be addressed to Jacqueline Woolley, Department of Psychology, 108 East Dean Keeton Street, Stop A8000, The University of Texas, Austin, TX 78712, ph. 512-471-5196. woolley@ austin.utexas.edu..

Publisher's Disclaimer: This is a PDF file of an unedited manuscript that has been accepted for publication. As a service to our customers we are providing this early version of the manuscript. The manuscript will undergo copyediting, typesetting, and review of the resulting proof before it is published in its final citable form. Please note that during the production process errors may be discovered which could affect the content, and all legal disclaimers that apply to the journal pertain.

Preliminary results were presented at the 2011 Biennial meeting of the Society for Research in Child Development in Montreal, Canada, and final results were presented at the 2013 meeting of the Cognitive Development Society in Memphis, TN. 
are not real (e.g., illusions), and there are entities that exist yet are not visible (e.g., air). Children often confront mismatches between visibility and reality. Most characters on children's television are visible but do not exist in the real world. Germs, a common topic of conversation with children, are real but cannot be seen. The focus of this paper is how children come to understand invisibility, along with how they manage the relations between visibility and reality.

The concept of invisibility sits at the intersection of two important and well-studied ontological distinctions: (1) that between reality and fantasy, and (2) that between reality and appearance. Because visibility is so often a cue to existence, young children may easily misinterpret lack of visual evidence as a cue to fantastical status. At the same time, to understand that something invisible is actually real, one must be able to separate appearance from reality. Research reveals significant development in children's understanding of both of these distinctions between the ages of 3 and 7 (Flavell, Green, \& Flavell, 1986; Moll \& Tomasello, 2012; Morison \& Gardner, 1978; Sharon \& Woolley, 2004; Woolley, 1997; Woolley \& Wellman, 1990). Yet, because the majority of children's experiences in the world involve entities that are both real and visible, conceiving of entities that are real yet invisible, or not real and visible, may be especially challenging to young children. As Harris, Pasquini, Duke, Asscher, and Pons (2006) explain, children learn much about unobservable scientific and other cultural phenomena through the testimony of other people. Although children may hear about particular instances of invisibility (e.g., germs or angels) in this way, to fully understand the concept of invisibility, children must be able to divorce appearance (or lack thereof) from reality. Without this ability, one could not comprehend, for example, that the stars and planets, although visible at night, still exist during the day when one cannot see them. As such, an understanding of invisible entities may rest upon a basic understanding of the appearance-reality distinction. Investigating this relation is a secondary goal of the present studies.

Researchers to date have explored children's knowledge of three types of invisible real entities: mental states, germs, and dissolved particles. Wellman and colleagues have shown that by age 3 children understand much about mental states such as thoughts, emotions, dreams, and imagination (Estes, Wellman, \& Woolley, 1989; Wellman \& Estes, 1986; Woolley \& Wellman, 1993). Specifically, work by Wellman and Estes (1986; Estes, Wellman, \& Woolley, 1989) showed that children understand that people have mental states even though mental states cannot be seen in the same way as physical entities. Others have shown that by age 4 or 5 children understand the existence of germs and other invisible particles (e.g., sugar dissolved in water), and can use them to reason about cause and effect (Au, Sidle, \& Rollins, 1993; Kalish, 1996; Rosen \& Rozin, 1993). For example, children understand that germs, although invisible, can cause disease and that sugar is still in sugarwater even though, once dissolved, one cannot see it. Although this work provides valuable information about children's reasoning, children's concepts of invisibility are not the focus of these prior studies. In our research we aim to provide insight into children's conceptions of germs and other invisible entities.

There is limited research on children's concepts of invisible not-real entities. Kiessling, Russell, Whitehouse, and Perner (2013), using a perspective-taking task, showed that 
children younger than 5 do not differentiate between invisible agents and absent humans in terms of their visibility. That is, not until age 5 did children appear to comprehend fully the existence of an invisible being. Research by Bering and Parker (2006) indicates that not until age 7 do children grasp the possibility that invisible beings can have communicative powers. They told 3-7-year-olds about an invisible being, Princess Alice, who would communicate with them during the course of a game by giving them signs. When an unexpected event occurred (e.g., a picture of Princess Alice fell off the wall while children were playing the game), although half of 5-year-olds thought the event was caused by the invisible being, only the oldest children (7-year-olds) acknowledged the communicative intentions of the princess. Bering and Parker also report that the ability to provide a coherent definition of the word invisible increases between the ages of 3 and 5.

Harris et al. (2006) investigated 4-8-year-olds' concepts of entities that are unobservable (although not necessarily invisible), both real and pretend. They presented children with a number of real (e.g., germs) and fantastical (e.g., Santa Claus) entities and asked about their reality status. They report that children understand that invisible entities like germs exist and that fantastical entities like monsters do not. Given that the visual evidence for both types of entity is identical (i.e., there is none), Harris and colleagues reason that the type of testimony children receive about these entities plays a critical role in the formation of their concepts. However, although this study establishes that children think differently about unobservable real and fantastical entities, it is still unclear how children think about invisibility or about how visibility relates to reality status. Regarding the real entities used in the study by Harris and colleagues, children often responded that they did not know what germs and oxygen looked like, suggesting that they might believe they are invisible. The pretend entities (Santa, God, the Tooth Fairy, mermaids, ghosts, and monsters) are not all considered by adults to be invisible. It also seems unlikely that children conceived of them as invisible, as children in the study responded a little more than half the time that they knew what these entities looked like. Yet children were never queried specifically about the entities' visibility. In sum, it is unclear whether children use visibility as a cue to reality status.

Beyond the types of testimony children might receive about invisible real and pretend entities, there is at least one critical difference between them: they are invisible for different reasons. There are various physical reasons (e.g., size) that one cannot see most invisible real things with the naked eye. Because of this, with expertise, technology, or a change in state or conditions one could potentially see these entities. However, by definition, no amount of expertise, technology, or change in state would enable one to really see invisible pretend entities. The present research probes whether children understand these different senses of invisibility.

From an adult perspective, visibility and reality are orthogonal. However, it seems possible that children may find it harder to dissociate the two constructs. Although research has shown that children have formed concepts of entities like germs, mental states, and fairies, we do not know the extent of children's ability to reason about the visibility and reality status of these sorts of entities. Research on the appearance-reality distinction has shown that it is difficult for young children to think simultaneously about two conflicting representations of the same object (Flavell, Green, \& Flavell, 1986; Moll \& Tomasello, 
2012; Woolley \& Wellman, 1990). Because, in everyday experience, real entities are most often visible, and vice versa, children might expect reality and visibility to co-occur. Because of this it might be difficult for a child to think about something as being both invisible and real or as being both visible and not real. Thus, a secondary goal is to probe the relation between appearance-reality understanding and children's understanding of invisibility.

\section{Method}

\subsection{Participants}

Thirteen 3-year-olds ( 8 females; mean age 42.8 months, range 35-49 months, SD 3.9 months), 17 5-year-olds (11 females; mean age 64.4 months, range 58-72 months, $S D 4.1$ months), and 17 7-year-olds (11 females; mean age 90.2 months, range 85-95 months, $S D$ 2.9 months) were recruited from a participant database and from a university preschool. Eighty-three percent were White, $8 \%$ were Hispanic, $4 \%$ were of more than one race, $2 \%$ were Asian, and 2\% did not report ethnicity. Each child was seen individually for one 15minute session. Children who were interviewed at the lab received a small toy or T-shirt for participating.

\subsection{Materials}

For the entity tasks, the name of each entity was printed on an individual laminated card (cards did not contain pictures of the entities). Two cylindrical boxes were used for sorting the cards; one had a "real" label with a photograph of a cat and the other a "pretend" label with a drawing of a fish singing into a microphone. Stimuli for the warm-up task consisted of two entities that were unambiguously real (a dog) or pretend (a dancing carrot). As shown in Figure 1, stimuli for test items varied in terms of reality status (real, not-real) and visibility (visible, invisible), resulting in a $2 \times 2$ design. In total, there were 12 test items in four categories: real visible (orange juice, teacher, bike), real invisible (germs, air, song), not-real visible (SpongeBob, mermaid, magic wand), and not-real invisible [W1] (ghost, imaginary friend, magic spell). The stimuli used for the appearance-reality tasks consisted of two realistic-looking imitation objects: an imitation rock made out of a soft, sponge-like material and a candle that looked like an apple. A small hand puppet was used for the appearance-reality task warm-up, and a picture of a microscope was used for the expert/ technology questions.

\subsection{Procedure}

Children completed two tasks: (1) an entities task, and (2) a standard appearance-reality task. All children received the tasks in this order.

2.3.1 Entities task-Children were told that they would be playing a game in which they needed to decide whether certain things are real or not real. Children first received a warmup task allowing them to practice providing both responses. Children were told, "This card says dog/dancing carrot. Is a dog/dancing carrot real or pretend?" The experimenter then corroborated or corrected the child's answer and asked the child to place the card in the appropriate real or pretend box. If children missed one or both questions the task was 
repeated with two more unambiguous entities. For each test item, the experimenter drew a card from a bag and stated, "This card says X." Children were then asked two questions about each item, first one about visibility and then one about reality status. These will be described in turn.

For the visibility question, children were asked, "Can you see $\mathrm{X}$ with your eyes or can you not see it?" Correct responses to the visibility question were scored as 1 ("can see" for visible entities and "cannot see" for invisible entities) and incorrect responses were scored as 0 .

For the reality status question, children were asked, "What do you think, is X real or pretend?" and asked to place the card in the appropriate box. (Children's verbal responses to the questions were recorded; the boxes were primarily designed as a means of making the task more fun and so box placement of the cards was not recorded.) Correct responses were scored as 1 ("real" for real entities and "not-real" or "pretend" for not-real entities) and incorrect responses were scored as 0 . The order of "real" and "pretend" options in the questions was counterbalanced across two participant response forms.

If children claimed that they could not see an entity, four follow-up questions were asked immediately following children's response to both the visibility and reality questions for that item. These questions were aimed at assessing whether, when children claim that various entities are invisible, they mean "entirely inaccessible to vision" or just "difficult (for them, or ordinary others) to see." Questions were asked in this order: (1) "Why can't you see X?", (2) "Can scientists (or another expert) ${ }^{1}$ see X?"; (3) "If we had a microscope could we see X?", and (4) "If we had a lot of light could we see X?". A picture of a microscope was placed on the table during the microscope question. Answers to the "Why can't you see X?" question were coded into five categories: (1) invisibility, which comprised explicit use of the word "invisible", (2) physical, which involved references to a physical property or location (e.g., "Because it's too small” or "They're under your skin"), (3) human production/sense, which referred to a human ability or lack thereof (e.g., "You can only feel it"), (4) reality status, which appealed to the real or pretend nature of the entity, and (5) uncodable. A second coder coded $50 \%$ of the responses; inter-rater agreement was $94 \%$ (Cohen's Kappa $=.93)$.

2.3.2 Appearance-reality task-After the familiar entities task, two standard appearance-reality tasks were administered: the sponge-rock and the apple-candle tasks used by Flavell et al. (1983). For each task, children were assigned a 1 for answering both the appearance and the reality questions correctly and a 0 otherwise; thus, scores could range from $0-2$. For grouping analyses, these were converted to high (score of 2 ) or low (0 or 1) scores.

${ }^{1}$ A scientist was the expert for most items. However for certain items different "experts" were used: For imaginary friends, a teacher was the expert, a magician was used for magic spell and magic wand, and for mermaids, a fisherman was the expert. 


\section{Results}

We begin by assessing the effects of the visibility and reality status of each item on children's visibility (“Can you see X?") and reality status (“Is X real or pretend?") judgments. Following that, we create a variable (visibility-reality score) that combines answers to visibility and reality status questions for each item, allowing us to assess children's ability to make the visibility-reality distinction for each type of entity. Lastly, we address children's explanations for the items they claimed they could not see, along with their responses to the follow-up questions regarding whether those items could be visible with expertise or technology.

\subsection{Visibility responses}

Children's scores were averaged within entity types; Table 1 displays the scores (out of 1), standard deviations, and comparisons to chance performance. Inspection of Table 1 shows that children performed significantly above chance on most entities and better on real than on not-real entities. A 3 (age: $3,5,7) \times 2$ (visibility status: visible, invisible) $\times 2$ (reality status: real, not-real) mixed analysis of variance (ANOVA) on the mean scores revealed a main effect of age, $F(2,44)=22.73, p<.001, \eta_{\mathrm{p}}{ }^{2}=.508$. Post-hoc tests (Tukey's Honestly Significant Difference, or HSD) indicated that 3-year-olds $(M=.63, S D=.34)$ were significantly less accurate than both 5-year-olds $(M=.81, S D=.23, p<.001)$ and 7-yearolds $(M=.86, S D=.21, p<.001)$. Reality status affected children's visibility responses, $F(1,44)=42.09, p<.001, \eta_{\mathrm{p}}{ }^{2}=.489$, with children performing significantly better on real $(M=.90, S D=.20)$ than on not-real $(M=.66, S D=.37)$ entities.

A significant interaction was also found between visibility status and reality status, $F(1,44)$ $=4.32, p=.044, \eta_{\mathrm{p}}^{2}=.089$. Post hoc tests (Tukey's HSD, $p<.01$ ) indicated that although children performed significantly better on visible real (e.g., bike; $M=.97, S D=.12$ ) than on visible not-real entities (e.g., SpongeBob; $M=.63, S D=.39$ ), and also on invisible real (e.g., germs, $M=.83, S D=.29$ ) versus invisible not-real entities (e.g., ghosts, $M=.69, S D=.35$ ), the magnitude of the difference was significantly greater for the visible entities $\left(M_{\text {difference }}\right.$ $=.34$ ) than for the invisible entities $\left(M_{\text {difference }}=.14\right)$. In summary, children's judgments of whether they could see an entity were affected by that entity's reality status: they were more likely to say they could see real entities, both visible and invisible, than not-real ones.

Table 2 shows the number of children in each age group who were correct on zero, one, two, or three items within each entity type. Statistical analyses, by binomial tests, of the probability of responding correctly on three of three items confirm the findings from the group analysis and provide additional information on the nature of the group means. First, for all items on which 3-year-olds performed at chance as a group (all quadrants in Figure 1 except real/visible), responses were fairly evenly distributed across the four response patterns. Additionally, responses of the 7-year-olds on the not-real visible entities (e.g., SpongeBob) were bimodally distributed, with the majority of children responding consistently that either these entities could be seen or that they could not be seen. 


\subsection{Reality Status Judgments}

Table 3 displays mean scores, standard deviations, and comparisons to chance performance for the reality status question. Children performed significantly above chance on most entities here as well. A 3 (age: $3,5,7) \times 2$ (visibility status: visible, invisible) $\times 2$ (reality status: real, not-real) mixed ANOVA revealed a main effect of age, $F(2,44)=29.55, p<$. $001, \eta_{\mathrm{p}}{ }^{2}=.573$. Post hoc tests (Tukey's HSD) indicated that 3-year-olds $(M=.59, S D=.26)$ performed significantly worse than both 5-year-olds $(M=.79, S D=.26, p<.001)$ and 7year-olds $(M=.95, S D=.12, p<.001)$, and 5-year-olds performed significantly worse than 7 -year-olds $(p=.005)$. There was also a main effect of reality status, $F(1,44)=18.40, p<$. $001, \eta_{\mathrm{p}}{ }^{2}=.295$, with children performing significantly better on real $(M=.88, S D=.22)$ than on not-real entities $(M=.70, S D=.33)$.

A significant interaction was also found between visibility and reality status, $F(1,44)=$ $12.18, p<.001, \eta_{\mathrm{p}}^{2}=.217$. Post hoc tests (Tukey's HSD) indicated that, for the real entities, children performed better on visible entities $(M=.94, S D=.15)$ than on invisible ones $(M$ $=.81, S D=.29), p=.009$.For the not-real entities the reverse was true: children performed better on invisible $(M=.76, S D=.29)$ than on visible entities $(M=.65, S D=.36), p=.037$. Children also performed significantly better on visible real $(M=.94, S D=.15)$ than on visible not-real entities $(M=.65, S D=.36), p<.001$. In summary, visibility affected children's reality status judgments, with children's correct answers to the reality status question varying as a function of the entity's visibility.

Table 4 shows the number of children in each age group who were correct on zero, one, two, or three items within each entity type. Statistical analyses, by binomial tests, of the probability of responding correctly on three of three items confirm the findings from the group analysis and provide additional information regarding the nature of the group means. We note two patterns: (1) except for the real visible entities, most 3-year-olds responded randomly, and (2) on the not-real visible entities (e.g., SpongeBob), 5-year-olds' responses were fairly evenly distributed across the four response patterns, but most answered correctly on two or three of the three entities.

To investigate the role of appearance-reality (AR) understanding on reality status judgments, a 2 (AR understanding: low, high) $\times 4$ (entity type: real visible, real invisible, not-real visible, not-real invisible) mixed analysis of covariance (ANCOVA) was conducted using age in months as a covariate. Children who passed both AR tasks were considered high in AR understanding; all others were considered low in AR understanding. Results showed that children with high AR understanding $(M=.84, S D=.11)$ performed significantly better overall on the reality status question than children with low understanding $(M=.72, S D=$. 12), $F(1,39)=5.83, p=.021, \eta_{\mathrm{p}}^{2}=.13$.

\subsection{Visibility-Reality scores}

If children expect reality and visibility to align, then entities for which they do not align (e.g., germs) should be harder to reason about than entities for which they do (e.g., bikes). For each item, if children correctly answered both the visibility and reality status questions, they received a score of 1 ; incorrect answers to either or both were scored as 0 . Table 5 
displays the percentage of correct responses (calculated out of three possible correct answers for each item type), standard deviation, and comparisons to chance performance, and indicates that children performed quite well on real visible entities (e.g., bike), but not as well on the other three types of entities. Specifically, there were developmental trends for both types of invisible entities. For invisible real entities (e.g., germs), 3-year-olds were at chance, 5-year-olds trended toward being above chance, and 7-year-olds were significantly above chance. Similarly, for the invisible not-real entities (e.g., ghosts), whereas 3-year-olds were significantly below chance, and 5-year-olds at chance, 7-year-olds performed significantly better than chance.

A 3 (age: 3, 5, 7) $\times 4$ (entity type: real visible, real invisible, not-real visible, not-real invisible) ANOVA on these scores revealed a main effect of age, $F(2,43)=35.62, p<.001$ and a main effect of entity type, $F(3,129)=27.39, p<.001$. Post-hoc tests (Tukey's HSD) indicated that 3-year-olds $(M=.39, S D=.14)$ performed significantly worse than both 5year-olds $(M=.69, S D=.14)$ and 7-year-olds $(M=.81, S D=.14)$, $p$ 's < .001. Five-yearolds also performed significantly worse than 7-year-olds, $p=.034$.

Paired sample $t$-tests were conducted to explore the main effect of entity type. Results indicated that children performed better on real visible items $(M=.92, S D=.20)$ than on real invisible items $(M=.70, S D=.36), t(46)=4.22$, on not-real visible items $(M=.38, S D$ $=.38), t(46)=9.46$, and on not-real invisible items $(M=.59, S D=.37), t(45)=6.36$, all $p \mathrm{~s}$ $<.001$. Children also performed better on both types of invisible entities than on not-real visible entities: for real invisible vs. not-real visible, $t(46)=5.04, p<.001$; for not-real invisible vs. not-real visible, $t(45)=3.05, p=.004$. Performance on the two types of invisible entities did not differ significantly $(p=.092)$. In summary, results indicate that maintaining a dual representation of an entity's visibility and reality status is easiest when the entity is both real and visible. Conceiving of an entity that is invisible or not real or both is more difficult.

We explored the relation between AR understanding and visibility-reality scores using a 2 (AR: high, low) $\times 4$ (entity type: real visible, real invisible, not-real visible, not-real invisible) ANCOVA, with age entered as a covariate. Results revealed a significant main effect of item type, as discussed above, as well as a significant effect of AR understanding, $F(1,41)=9.69, p=.003, \eta_{\mathrm{p}}{ }^{2}=.19$. Even controlling for age, children with high AR scores had higher visibility-reality scores overall $(M=2.05, S D=.41)$ than did children with low AR scores $(M=1.61, S D=.40)$.

\subsection{Explanations}

As shown in Figure 1, children's explanations for why they could not see invisible entities varied according to whether the entity was real or not. To explore these patterns statistically, a 3 (age: $3,5,7) \times 2$ (entity type: real, not-real) $\times 4$ (explanation type: invisibility, physical, human production/sense, reality status) ANOVA was conducted on children's explanations. The analysis revealed a main effect of explanation type, $F(3,117)=2.83, p=.04, \eta_{\mathrm{p}}{ }^{2}=.07$, which was subsumed by an explanation type $\times$ entity interaction, $F(3,117)=35.94, p<.001$, $\eta_{\mathrm{p}}{ }^{2}=.48$. This, in turn, was subsumed by a significant item type $\times$ explanation $\times$ age interaction, $F(6,117)=4.61, p<.001, \eta_{\mathrm{p}}{ }^{2}=.19$. Thus the item type $\times$ explanation interaction was explored separately for each age group. Three-year-olds' explanations did 
not differ significantly for real and not-real entities, whereas both 5-year-olds', $F(3,45)=$ $11.12, p<.001, \eta_{\mathrm{p}}{ }^{2}=.43$, and 7-year-olds', $F(3,36)=15.04, p<.001, \eta_{\mathrm{p}}{ }^{2}=.56$, did. Fiveyear-olds used physical explanations more for real entities $(M=1.0$, out of $3, S D=.73)$ than for not-real entities $(M=.38, S D=.62), t(15)=3.1, p=.007$, and also used human production/sense explanations more for real $(M=.50, S D=.52)$ than for not-real entities $(M$ $=0.0), t(15)=3.87, p=.002$. Five-year-olds also used reality status explanations more for not-real entities $(\mathrm{M}=1.06, S D=.93)$ than for real entities $(M=0.0), t(15)=-4.58, p<.001$. Patterns for 7-year-olds were similar, with more physical explanations given for real entities $(M=1.15, S D=.80)$ than not-real entities $(M=0.0), t(12)=5.20, p<.001$, and more reality status explanations given for not-real entities $(M=1.92, S D=.95)$ than for real entities $(M$ $=0.0), t(12)=-7.27, p<.001$.

\subsection{Expert/technology questions}

For each entity, we calculated the number of children who responded affirmatively to at least one of the three questions, thus indicating that they thought, despite initially responding that they couldn't see the entity, that there was still some way (either via an expert, more light, or a microscope) to see it. For the real entities (germs, air, songs), children's responses varied according to the specific entity. Almost all of these children claimed that there was some way to see germs (between 86 and 100\%). Responses regarding air did not differ by age group, with $40 \%$ of 3 -year-olds, $60 \%$ of 5 -year-olds, and $24 \%$ of 7 -year-olds claiming there was some way to see air. There was a clear developmental trend for songs, with most 3 -year-olds $(75 \%)$ and about half of the 5-year-olds $(58 \%)$ claiming that there was some way to see them, whereas no 7-year-old claimed this, $p<.001$, using Fisher's Exact test. For the not-real entities, there was a clear decrease with age in the number of children claiming there was some way these entities could be seen. Responses did not vary by item (ghosts, imaginary companions, magic spell). Overall, $88 \%$ of 3 -year-olds, $62 \%$ of 5 -year-olds, and $18 \%$ of 7 -year-olds answered that there was some way to see the not-real invisible entities, $\boldsymbol{X}^{2}(2)=32.35, p<.001$. These patterns suggest that, with age, it may become easier for children to conceive of entities that, in principle, cannot be seen (versus simply being difficult to see).

Analysis of each of the three expert/technology questions individually yielded significant effects only for the microscope question. A 3 (age: $3,5,7) \times 2$ (reality status: real, not-real) mixed analysis of variance revealed a main effect of age, $F(2,37)=7.48, p=.002, \eta_{\mathrm{p}}{ }^{2}=$. 29 , as well as a main effect of reality status, $F(1,37)=5.69, p=.022, \eta_{\mathrm{p}}{ }^{2}=.13$. As displayed in Figure 2, a significant interaction was also found between age and reality status, $F(2,37)=3.76, p=.033, \eta_{\mathrm{p}}^{2}=.17$. Post hoc tests (Tukey's HSD) indicated that 3 -year-olds were significantly more likely than 7 -year-olds $(p=.002)$ to say that one could use a microscope to see the real entities. For the not-real entities, both 3 -year-olds $(p=.002)$ and 5 -year-olds ( $p=.015$ ) were significantly more likely than 7-year-olds to say that you could use a microscope to see them. Analyses also indicated that 7 -year-olds $(p<.001)$ were the only age group to differentiate the two types of entities, claiming more often that one could use a microscope to see real entities than that one could use a microscope to see not-real entities, $t(16)=5.22, p<.001$ ( 2 tailed). These results indicate that not until age 7 did children clearly and consistently conceive of entities that are, by definition, un-seeable. 
Thus, by age 7 children appear to consider invisible real and not-real entities as exhibiting fundamentally different types of invisibility.

\section{Discussion}

Our goal was to explore conceptual development at the intersection of two important ontological distinctions: reality/appearance and reality/non-reality. Children's concepts of invisibility, which lie at this juncture, are active in both their reasoning and behavior concerning real-world phenomena, like germs and air, and entities common in their fantasy lives, such as imaginary companions and ghosts. Our results demonstrate that young children's concepts of visibility and reality are intertwined. We found that an entity's reality status affected claims about visibility, and an entity's visibility affected claims about reality status. Specifically, regarding visibility, children were more likely to say that they could see real entities, both visible and invisible, than not-real entities. Regarding reality status, they were more likely to say that real visible items were real compared to real invisible items, and that invisible not-real items were not real compared to visible not-real items. With age, children performed better on both visibility and reality status questions, indicating that these concepts become disentangled as children develop.

Our results also indicate that children's ability to maintain concurrent representations of the visibility and reality status of various entities increased significantly between ages 3 and 7 , and varied as a function of the type of entity involved. Additionally, irrespective of age, children who performed well on standard appearance-reality (AR) tasks were significantly better at reasoning simultaneously about the visibility and reality of entities. Moll and Tomasello (2012) describe development in AR understanding as becoming able "to confront (the) two perspectives on the same object simultaneously" (p. 1125), and interpret children's failures on AR tasks not as demonstrating a lack of understanding of appearance and reality, but as an inability to dually represent these conflicting properties. The real-visible entities in our study were the only ones for which 3-year-olds answered both visibility and reality status questions correctly at a level greater than chance. This suggests that, to them, reasoning about these sorts of entities does not involve "confronting different properties"certainly in their experience (and in that of adults as well) real and visible most often cooccur. Young children may, at first, simply expect real things to be visible, and vice versa. To the extent that real and visible are initially inextricably linked in the young child's mind, entities that violate this link can be thought of as requiring a confrontation of conflicting properties.

Children's ability to dually represent the visibility and reality status of the two types of invisible entities (real and not-real) improved with age, with only 7-year-olds performing at above chance levels. It is important to note that, when examining children's answers to the visibility questions or the reality status questions alone, 5-year-olds performed above chance, indicating that their poor performance on the visibility-reality tasks does not indicate that they fail to understand visibility and reality, but rather that they have difficulty when asked to confront the two perspectives at the same time. Although this conflict model might predict that visibility-reality reasoning would be easy for not-real invisible entities (because the visible real pairing is not violated), familiarity may also have played a role, resulting in 
children performing more poorly on these entities than on real visible ones. This model also predicts the observed poor overall performance on the not-real visible entities. However, another factor that may have contributed to children's poor performance on these items is ambiguity in interpretation of the visibility question. Specifically, the overall poor performance of even 7-year-olds on the not-real visible items, and the bimodal distribution of their responses, suggests that some children may have interpreted this question as asking whether the entities could be seen in real life, rather than just on television or in books.

Lastly, the results of our study provide new insight into how children think about different kinds of invisible phenomena. Children's explanations for why they could not see invisible real and not-real entities indicated that, by age 5, children were thinking differently about the two types of entities; they were more likely to explain the invisibility of real entities, like germs, by referring to their physical properties or lack thereof, whereas they were more likely to explain the invisibility of not-real entities, like ghosts, with reference to reality status. We observed a related development in children's responses regarding whether one could see, with additional expertise or technology, both invisible real and invisible not-real entities. Here it was not until age 7 that children responded differently for invisible real versus invisible not-real entities, claiming that only the former could ultimately be seen with a microscope. Thus, the understanding that certain invisible pretend entities are truly and necessarily un-seeable, and hence that real and not-real invisibility are fundamentally different, appears to develop significantly between the ages of 3 and 7.

There were also hints that children perceived differences in types of invisibility within the real entities. Real entities can be invisible for a variety of reasons. Entities like germs are invisible because they are too small to be seen by the naked eye, but could be seen with the aid of technology. Oxygen molecules and sound, on the other hand, cannot be seen with any technology that is currently available. The differences we observed on the expert/technology questions with respect to germs, air, and songs, suggest that even 3-year-olds might have some nascent awareness of these differences but also that understanding develops significantly between ages 3 and 7 . We suspect that early science instruction about these specific entities is likely to play a role in this increasing understanding.

In conclusion, the results of this study begin to provide some insight into how children wrestle with a distinctly difficult concept. Because of children's experiences in the world, they may form an initial expectation that visibility consistently co-occurs with reality. With age and experience, children's concepts of visibility and reality status become disentangled. Our results suggest that an ability to dually represent both an entity's visibility and its reality status develops significantly between the ages of 3 and 7 . This ability may be an extension of a more general dual representation ability that also enables children to represent an object's appearance when it differs from its real identity. Future studies might aim to address how information available in other people's testimony interacts with children's ability to dually represent visibility and reality status. Finally, our results indicate that children's concepts of invisibility become richer with age, allowing for two types of invisibility-one by definition, as often encountered in fantasy and fiction, and one that can be surmounted by technology. 


\section{Acknowledgements}

This research was partially funded by NICHD grant HD-30300 to Jacqueline D. Woolley. We would like to thank Sweta Daru, Brittany Kinard, and Annette Leija for their help with data collection and Chelsea Cornelius and Gabe Lopez-Mobilia for feedback on earlier drafts. This research was conducted as Melissa McInnis's Undergraduate Honors Thesis. We offer our greatest thanks to the children and parents who participated at the Children's Research Lab.

\section{References}

Au TK, Sidle A, Rollins K. Developing an intuitive understanding of conservation and contamination: Invisible particles as a plausible mechanism. Developmental Psychology. 1993; 29:286-299. doi: 10.1037/0012-1649.29.2.286.

Bering JM, Parker BD. Children's attributions of intentions to an invisible agent. Developmental Psychology. 2006; 42(2):253-262. doi: 10.1037/0012-1649.42.2.253. [PubMed: 16569164]

Estes, D.; Wellman, HM.; Woolley, J. Children's understanding of mental phenomena. In: Reese, H., editor. Advances in child development and behavior. Academic Press; New York: 1989. p. 41-86.

Flavell JH, Green FL, Flavell ER. Development of knowledge about the appearance-reality distinction. Monographs of the Society for Research in Child Development. 1986; 51(1, Serial No. 212) doi: 10.2307/1165866.

Harris PL, Pasquini ES, Duke S, Asscher JJ, Pons F. Germs and angels: The role of testimony in young children's ontology. Developmental Science. 2006; 9:76-96. doi: 10.1111/j. 1467-7687.2005.00465.x. [PubMed: 16445398]

Kalish CW. Preschoolers' understanding of germs as invisible mechanisms. Cognitive Development. 1996; 11(1):83-106. doi: 10.1016/S0885-2014(96)90029-5.

Kiessling, F.; Russell, YI.; Whitehouse, H.; Perner, J. Young children's understanding of invisibility: Acquiring the ideas of invisible presence and an unseen seer. University of Salzburg; 2013. Unpublished paper

Meltzoff AN, Waismeyer A, Gopnik A. Learning about causes from people: Observational causal learning in 24-month-old infants. Developmental Psychology. 2012; 48:1215-1228. doi: 10.1037/ a0027440. [PubMed: 22369335]

Moll H, Tomasello M. Three-year-olds understand appearance-reality-Just not about the same object at the same time. Developmental Psychology. 2012; 48:1124-1132. doi: 10.1037/a0025915. [PubMed: 22040314]

Morison P, Gardner H. Dragons and dinosaurs: The child's capacity to differentiate fantasy from reality. Child Development. 1978; 49:642-648. doi: 10.2307/1128231.

Piaget, J. Play, Dreams and Imitation in Childhood. Norton; New York: 1962.

Rogoff B, Paradise R, Arauz RM, Correa-Chávez M, Angelillo C. Firsthand learning through intent participation. Annual Review of Psychology. 2003; 54:175-203. doi: 10.1146/annurev.psych. 54.101601.145118.

Rosen A, Rozin P. Now you see it, now you don't: The preschool child's conception of invisible particles in the context of dissolving. Developmental Psychology. 1993; 29:300-311. doi: 10.1037/0012-1649.29.2.300.

Sharon T, Woolley JD. Do monsters dream? Young children's understanding of the fantasy/reality distinction. British Journal of Developmental Psychology. 2004; 22:293-310. doi: 10.1348/026151004323044627.

Wellman HM, Estes D. Early understanding of mental entities: A reexamination of childhood realism. Child Development. 1986; 57:910-923. doi: 10.2307/1130367. [PubMed: 3757609]

Williamson RA, Jaswal VK, Meltzoff AN. Learning the rules: Observation and imitation of a sorting strategy by 36-month-old children. Developmental Psychology. 2010; 46:57-65. doi: 10.1037/ a0017473. [PubMed: 20053006]

Woolley JD. Thinking about fantasy: Are children fundamentally different thinkers and believers from adults? Child Development. 1997; 68:991-1011. doi: 10.2307/1132282. [PubMed: 9418217] 
Woolley JD, Wellman HM. Young children's understanding of realities, nonrealities, and appearances. Child Development. 1990; 61:946-961. doi: 10.2307/1130867. [PubMed: 2209198]

Woolley JD, Wellman HM. Origin and truth: Young children's understanding of imaginary mental representations. Child Development. 1993; 64:1-17. doi: 10.2307/1131434. [PubMed: 8436024] 


\section{Highlights}

- Young children's concepts of visibility and reality are intertwined.

- Children's ability to dually represent visibility and reality develops between 3 and 7.

- Recognition that real and not-real invisibility differ develops between 3 and 7 .

- Performance on appearance-reality tasks is related to reasoning about invisibility. 


\section{Reality Status}

\begin{tabular}{|c|c|c|}
\hline & & Not Real \\
\hline Visible & $\begin{array}{l}\text { Orange juice } \\
\text { Teacher } \\
\text { Bike }\end{array}$ & $\begin{array}{l}\text { SpongeBob } \\
\text { Mermaid } \\
\text { Magic wand }\end{array}$ \\
\hline Invisible & $\begin{array}{l}\text { Germs } \\
\text { Air } \\
\text { Song }\end{array}$ & $\begin{array}{l}\text { Ghost } \\
\text { Imaginary friend } \\
\text { Magic spell }\end{array}$ \\
\hline
\end{tabular}

Figure 1.

Stimuli. 


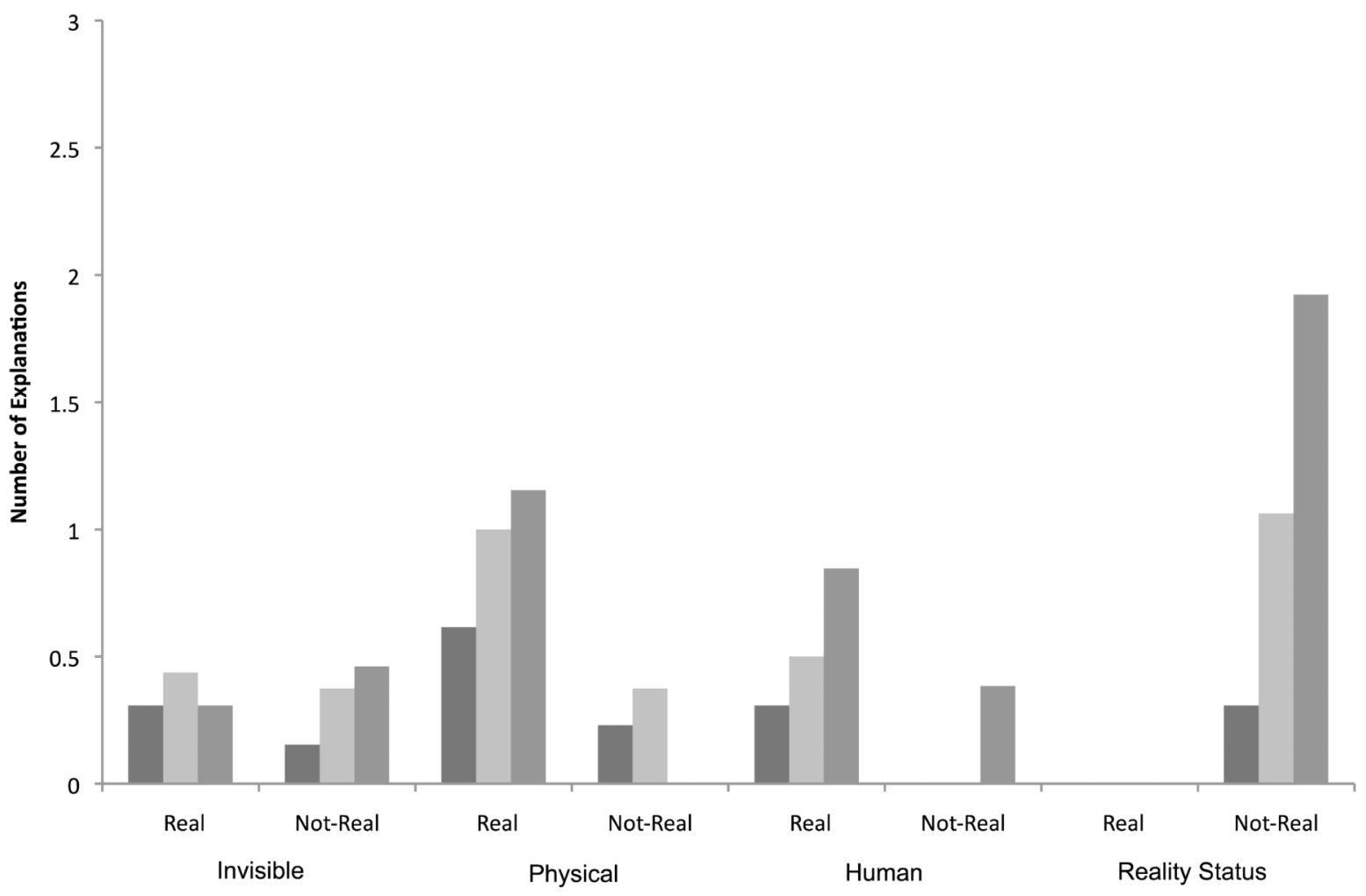

" 3-year-olds

5-year-olds

a-year-olds

Figure 2.

Explanations for why real and not-real invisible entities could not be seen. 


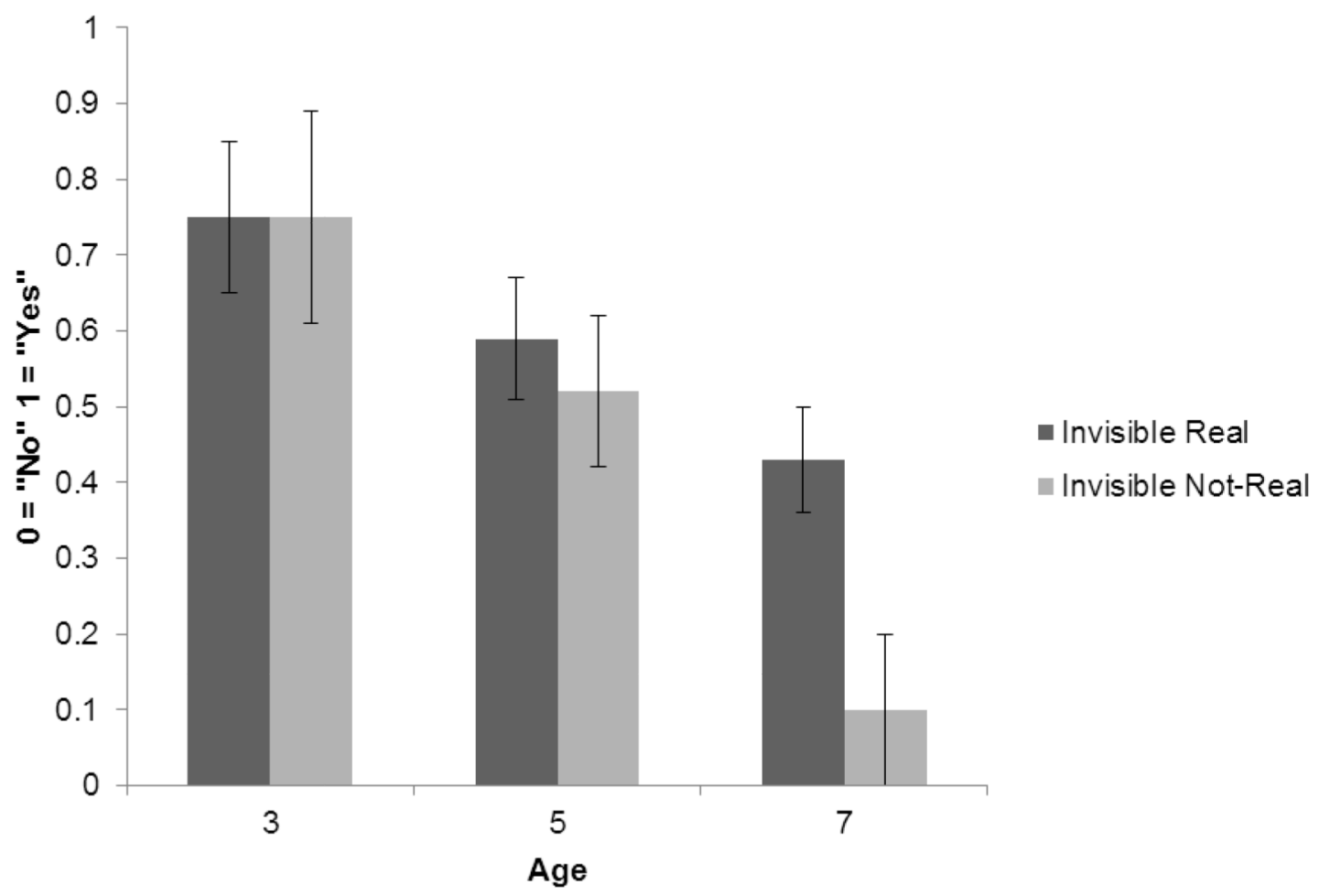

Figure 3.

Interaction of age and reality status for "If we had a microscope, could we see X?" 
Table 1

Visibility Question: Mean scores, standard deviations, and chance tests

\begin{tabular}{|c|c|c|c|}
\hline & $M$ & $S D$ & $t, p$ \\
\hline \multicolumn{4}{|l|}{ Real Entities } \\
\hline \multicolumn{4}{|l|}{ Visible } \\
\hline 3-year-olds & .90 & .21 & $6.82, p<.001$ \\
\hline 5-year-olds & 1.0 & .00 & $*$ \\
\hline 7-year-olds & 1.0 & .00 & $*$ \\
\hline Total & .97 & .12 & $27.65, p<.001$ \\
\hline \multicolumn{4}{|l|}{ Invisible } \\
\hline 3-year-olds & .64 & .37 & $\mathrm{~ns}$ \\
\hline 5-year-olds & .84 & .24 & $5.91, p<.001$ \\
\hline 7-year-olds & .96 & .16 & $11.75, p<.001$ \\
\hline Total & .83 & .29 & $7.92, p<.01$ \\
\hline \multicolumn{4}{|l|}{ Not-real Entities } \\
\hline \multicolumn{4}{|l|}{ Visible } \\
\hline 3-year-olds & .56 & .39 & ns \\
\hline 5-year-olds & .71 & .33 & $2.57, p=.02$ \\
\hline 7-year-olds & .61 & .46 & ns \\
\hline Total & .63 & .39 & $2.28, p=.03$ \\
\hline \multicolumn{4}{|l|}{ Invisible } \\
\hline 3-year-olds & .44 & .37 & ns \\
\hline 5-year-olds & .68 & .34 & $2.24, p=.04$ \\
\hline 7-year-olds & .88 & .20 & $7.8, p<.001$ \\
\hline Total & .69 & .35 & $3.69, p<.01$ \\
\hline
\end{tabular}

* Ceiling effect, no statistic computed. 
Table 2

Visibility Question: Individual subject patterns, with p-values for binomial tests

\begin{tabular}{|c|c|c|c|c|c|}
\hline & 0 Correct & 1 Correct & 2 Correct & 3 Correct & $p$ \\
\hline \multicolumn{6}{|l|}{ Real Entities } \\
\hline \multicolumn{6}{|l|}{ Visible } \\
\hline 3-year-olds & 0 & 1 & 2 & 10 & .035 \\
\hline 5-year-olds & 0 & 0 & 0 & 17 & $<.001$ \\
\hline 7-year-olds & 0 & 0 & 0 & 17 & $<.001$ \\
\hline Total & 0 & 1 & 2 & 44 & \\
\hline \multicolumn{6}{|l|}{ Invisible } \\
\hline 3-year-olds & 2 & 2 & 4 & 5 & $n s$ \\
\hline 5-year-olds & 0 & 2 & 4 & 11 & $n s$ \\
\hline 7-year-olds & 0 & 1 & 0 & 16 & $<.001$ \\
\hline Total & 2 & 5 & 8 & 32 & \\
\hline \multicolumn{6}{|l|}{ Not-real Entities } \\
\hline \multicolumn{6}{|l|}{ Visible } \\
\hline 3-year-olds & 3 & 2 & 4 & 4 & $n s$ \\
\hline 5-year-olds & 1 & 4 & 4 & 8 & $n s$ \\
\hline 7-year-olds & 5 & 2 & 1 & 9 & $n s$ \\
\hline Total & 9 & 8 & 9 & 21 & \\
\hline \multicolumn{6}{|l|}{ Invisible } \\
\hline 3-year-olds & 4 & 3 & 4 & 2 & $n s$ \\
\hline 5-year-olds & 1 & 5 & 3 & 8 & $n s$ \\
\hline 7-year-olds & 0 & 1 & 4 & 12 & .017 \\
\hline Total & 5 & 9 & 11 & 22 & \\
\hline
\end{tabular}

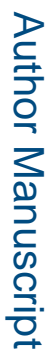

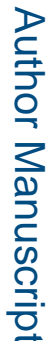

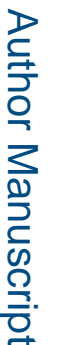

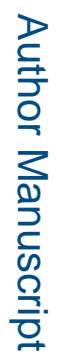

Cogn Dev. Author manuscript; available in PMC 2016 April 01. 
Table 3

Reality Status Question: Mean scores, standard deviations, and chance tests

\begin{tabular}{|c|c|c|c|}
\hline & $M$ & $S D$ & $t, p$ \\
\hline \multicolumn{4}{|l|}{ Real Entities } \\
\hline \multicolumn{4}{|l|}{ Visible } \\
\hline 3-year-olds & .81 & .22 & $4.75, p<.001$ \\
\hline 5-year-olds & 1.0 & .00 & $*$ \\
\hline 7-year-olds & 1.0 & .00 & $*$ \\
\hline Total & .94 & .14 & $21.77, p<.01$ \\
\hline \multicolumn{4}{|l|}{ Invisible } \\
\hline 3-year-olds & .56 & .30 & $\mathrm{~ns}$ \\
\hline 5-year-olds & .84 & .31 & $4.24, p<.001$ \\
\hline 7-year-olds & .98 & .08 & $24.5, p<.001$ \\
\hline Total & .82 & .29 & $7.38, p<.01$ \\
\hline \multicolumn{4}{|l|}{ Not-real Entities } \\
\hline \multicolumn{4}{|l|}{ Visible } \\
\hline 3-year-olds & .36 & .22 & ns \\
\hline 5-year-olds & .64 & .37 & ns \\
\hline 7-year-olds & .90 & .27 & $6.44, p<.001$ \\
\hline Total & .67 & .36 & $2.30, p<.01$ \\
\hline \multicolumn{4}{|l|}{ Invisible } \\
\hline 3-year-olds & .61 & .28 & ns \\
\hline 5-year-olds & .73 & .36 & $2.51, p=.03$ \\
\hline 7-year-olds & .90 & .16 & $10.59, p<.001$ \\
\hline Total & .77 & .29 & $5.78, p<.01$ \\
\hline
\end{tabular}

* Ceiling effect, no statistic computed. 
Table 4

Reality Status Question: Individual subject patterns, with p-values for binomial tests

\begin{tabular}{|c|c|c|c|c|c|}
\hline & 0 Correct & 1 Correct & 2 Correct & 3 Correct & $p$ \\
\hline \multicolumn{6}{|l|}{ Real Entities } \\
\hline \multicolumn{6}{|l|}{ Visible } \\
\hline 3 -year-olds & 0 & 1 & 5 & 6 & $n s$ \\
\hline 5-year-olds & 0 & 0 & 0 & 17 & $<.001$ \\
\hline 7-year-olds & 0 & 0 & 0 & 17 & $<.001$ \\
\hline Total & 0 & 1 & 5 & 40 & \\
\hline \multicolumn{6}{|l|}{ Invisible } \\
\hline 3-year-olds & 1 & 4 & 5 & 3 & $n s$ \\
\hline 5-year-olds & 1 & 2 & 2 & 12 & .047 \\
\hline 7-year-olds & 0 & 0 & 1 & 16 & .005 \\
\hline Total & 2 & 6 & 8 & 31 & \\
\hline \multicolumn{6}{|l|}{ Not-real Entities } \\
\hline \multicolumn{6}{|l|}{ Visible } \\
\hline 3-year-olds & 2 & 7 & 4 & 0 & $n s$ \\
\hline 5 -year-olds & 3 & 3 & 5 & 6 & $n s$ \\
\hline 7-year-olds & 1 & 0 & 2 & 14 & .005 \\
\hline Total & 6 & 10 & 11 & 20 & \\
\hline \multicolumn{6}{|l|}{ Invisible } \\
\hline 3-year-olds & 0 & 6 & 4 & 3 & $n s$ \\
\hline 5-year-olds & 1 & 4 & 1 & 9 & $n s$ \\
\hline 7-year-olds & 0 & 0 & 5 & 12 & .047 \\
\hline Total & 1 & 10 & 10 & 24 & \\
\hline
\end{tabular}

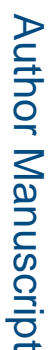

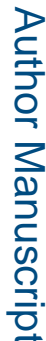

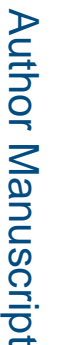

Cogn Dev. Author manuscript; available in PMC 2016 April 01. 
Table 5

Visibility-Reality Scores: Mean scores, standard deviations, and chance tests

\begin{tabular}{lccc}
\hline & $\boldsymbol{M}$ & $\boldsymbol{S D}$ & $\boldsymbol{t}, \boldsymbol{p}$ \\
\hline Real Entities & & & \\
Visible & & & \\
3-year-olds & .72 & .30 & $2.62, p=.02$ \\
5-year-olds & 1.0 & .00 & $*$ \\
7-year-olds & 1.0 & .00 & $*$ \\
Total & .92 & .20 & $14.52, p<.01$ \\
Invisible & & & \\
3-year-olds & .39 & .36 & $\mathrm{~ns}$ \\
5-year-olds & .71 & .32 & $1.94, p=.07$ \\
7-year-olds & .94 & .18 & $10.32, p<.001$ \\
Total & .70 & .36 & $3.48, p<.01$ \\
\hline
\end{tabular}

\begin{tabular}{lllc} 
Not-real Entities & & & \\
Visible & & & \\
3-year-olds & .15 & .22 & $-5.67, p<.001$ \\
5-year-olds & .41 & .33 & $\mathrm{~ns}$ \\
7-year-olds & .51 & .46 & $\mathrm{~ns}$ \\
Total & .38 & .38 & $-2.35, p=.02$ \\
Invisible & & & \\
3-year-olds & .28 & .27 & $-2.9, p=.01$ \\
5-year-olds & .63 & .40 & $\mathrm{~ns}$ \\
7-year-olds & .80 & .24 & $5.28, p<.001$ \\
Total & .59 & .37 & $\mathrm{~ns}$ \\
\hline
\end{tabular}

* Ceiling effect, no statistic computed. 